\title{
Estágio supervisionado obrigatório: atividades desenvolvidas pelos discentes do curso de Secretariado Executivo Bilíngue da UFPB
}

Required supervised training: activities developed by the students of the Bilingual Executive Secretariat course of the UFPB

\author{
Francisca Janete da Silva Adelino ${ }^{1(\mathbb{D})}$, Lauricélia Lima da Silva ${ }^{2(\mathbb{D})}$ \\ ${ }^{1}$ Universidade Federal da Paraíba (UFPB), Brasil, Doutora em Linguística (UFPB), professora no curso de Secretariado \\ Executivo Trilíngue (UFPB), e-mail: janete_adelino@hotmail.com \\ ${ }^{2}$ Universidade Federal da Paraíba (UFPB), Brasil, Bacharel em Secretariado Executivo Bilíngue (UFPB), e-mail: \\ lauri.lima.8@hotmail.com
}

\section{RESUMO}

Este estudo objetiva investigar as atividades desenvolvidas por estagiários do curso de Secretariado Executivo Bilíngue da UFPB, durante as disciplinas de estágio supervisionado II, III e IV. Para tanto, realizou-se uma pesquisa exploratória e documental, conduzida sob abordagem qualitativa e quantitativa. Os dados foram coletados por meio de relatórios de estágio, produzidos por discentes, nos períodos de 2017.1 e 2017.2. Entre os resultados encontrados, constatou-se que as atividades desenvolvidas pelos estagiários estão mais voltadas para o campo da assessoria e da consultoria. Observou-se que trinta empresas/instituições ofereceram oportunidades de estágio supervisionado. Destacou-se o âmbito público como aquele que mais oferta oportunidade de estágio.

Palavras-chave: Estágio supervisionado. Atividades desenvolvidas. Campo de estágio.

\begin{abstract}
This study aims to investigate the activities developed by trainees of the Bilingual Executive Secretariat course of UFPB, during the disciplines of supervised internship II, III and IV. For this, an exploratory and documentary research was carried out, conducted under a qualitative and quantitative approach. Data were collected through internship reports, produced by students, in the periods of 2017.1 and 2017.2. Among the results found, it was found that the activities developed by the trainees are more focused on the field of advisory and consulting. It was observed that thirty companies/institutions offered supervised internship opportunities. The public scope stood out as the one that most offer internship opportunity.
\end{abstract}

Keywords: Supervised Internship. Developed activities. Internship field. 


\title{
1 INTRODUÇÃO
}

O estágio supervisionado obrigatório no curso de Secretariado Executivo Bilíngue da Universidade Federal da Paraíba-UFPB, é dividido em quatro disciplinas, a saber: Estágio supervisionado I, II, III e IV, sendo que a primeira fase é trabalhada em sala de aula com conteúdo programático, que vai desde o resgate da teoria na área específica, fazendo uma ponte com a prática, incluindo discussões sobre a normatização, a ética e o papel do estagiário na organização, até a visão geral das instituições, nas quais os alunos almejam estagiar e finaliza com a elaboração de um projeto de estágio, para ser executado nas três fases seguintes.

De acordo com a Resolução 01/2009 que normatiza o estágio supervisionado no curso de Secretariado da UFPB, os estágios II, III e IV têm como objetivos:

\begin{abstract}
[...] inserir o aluno na realidade na qual irá atuar no âmbito das instituições públicas e privadas; possibilitar a identificação de limites e condições para o desenvolvimento da profissão de Secretariado Executivo, em uma perspectiva transformadora do exercício das funções secretariais; executar o projeto de estágio elaborado na primeira fase sob a orientação da professora da disciplina de Estágio Supervisionado I, avaliar o fazer profissional a partir da experiência vivenciada no campo de estágio e, por último elaborar e apresentar o relatório de estágio desenvolvido durante às três fases, conforme estabelecido na resolução de estágio do referido curso.
\end{abstract}

É por meio da prática desenvolvida durante as disciplinas de estágio supervisionado, que o aluno se depara com a realidade da profissão escolhida, as categorias de atividades, as responsabilidades que lhe compete e os diversos desafios conferidos à sua área. Além disso, o estágio também possibilita o desenvolvimento de habilidades de relacionamento interpessoal nos diversos setores da organização concedente, a interação com a cultura organizacional, o desenvolvimento de competências técnicas e a efetivação no próprio campo de estágio. Essa efetivação pode surgir tanto na organização concedente quanto em outras empresas, por intermédio de clientes e fornecedores, considerando que durante o estágio é possível construir uma rede de relacionamentos no próprio campo.

Na medida em que o estagiário vai se descobrindo em sua área de atuação por meio da vivência de situações reais do mundo do trabalho, vai também aprendendo a lidar com os desafios, dificuldades e cenários diversos relacionados às atribuições da profissão escolhida. Certamente, essas descobertas propiciam, além da experiência e do aprendizado necessário para adentrar no mercado de trabalho, a compreensão da sua identidade profissional durante esse

Revista Expectativa, Toledo/PR, v.20, n. 3, p. 108-130, jul./set., 2021. 
processo de aprendizagem, por meio de uma autoavaliação do que precisa ser melhorado, no tocante aos seus pontos fortes e fracos.

Diante da importância do estágio supervisionado na formação do aluno, pretende-se com esta investigação obter respostas para a seguinte questão: Quais atividades são desenvolvidas por discentes do curso de Secretariado Executivo Bilíngue da UFPB e quais empresas/instituições esses estagiários estão desenvolvendo suas práticas?

Assim, o objetivo geral desta pesquisa é investigar as atividades desenvolvidas por estagiários do curso de Secretariado Executivo Bilíngue da UFPB, durante as disciplinas de estágio supervisionado II, III e IV. Especificamente, mapear as atividades de estágio; verificar se as atividades realizadas no estágio II se repetem nos estágios III e IV e catalogar as empresas/instituições concedentes.

Para tanto, busca-se trilhar os objetivos propostos por meio de uma pesquisa documental que emprega tanto a abordagem quantitativa quanto a qualitativa. O estudo é relevante, visto que procura mapear as atividades desenvolvidas por estudantes durante a fase prática de suas formações relativas ao estágio supervisionado.

O artigo segue estruturado em mais quatro seções: na segunda seção apresentam-se a revisão bibliográfca sobre estágio supervisionado bem como abordam-se os campos de atuação profissional; na terceira seção, descrevem-se os procedimentos metodológicos; na quarta, destacam-se a análise dos resultados e na quinta apresentam-se as considerações finais do estudo.

\section{REVISÃO TEÓRICA: ALGUMAS CONSIDERAÇÕES SOBRE O ESTÁGIO SUPERVISIONADO OBRIGATÓRIO}

A Lei 11.788/2008 assegura que o estágio é "o ato educativo escolar supervisionado, desenvolvido no ambiente de trabalho, que visa à preparação para o trabalho produtivo de educandos [...]" (BRASIL, 2008).

Portela e Schumacher (2007), complementam que o estágio é de suma relevância para o aluno, uma vez que propicia a este uma reflexão acerca da comprovação da escolha profissional; a vivência da realidade organizacional; a ampliação do conhecimento por meio da prática; o desenvolvimento de atividades que contribui para a formação profissional, bem como,

Revista Expectativa, Toledo/PR, v.20, n. 3, p. 108-130, jul./set., 2021. 
o desenvolvimento de habilidades e competências que servem de base para sua atuação futura no mercado de trabalho.

No que tange as habilidades e competências, Moretto (2002, p. 2) contribui dizendo que:

\begin{abstract}
As habilidades estão associadas ao saber fazer: ação física ou mental que indica a capacidade adquirida. [...] Já competências, é um conjunto de habilidades harmonicamente desenvolvidas e que caracterizam, por exemplo, uma função/profissão específica: ser arquiteto, médico ou professor de química. As habilidades devem ser desenvolvidas na busca das competências.
\end{abstract}

Portela e Schumacher (2007, p. 36) acrescentam que o estágio supervisionado faz parte de todos os cursos com o objetivo de contribuir com "a formação no sentido humano, técnicosocial, cultural, científico constituindo a ocasião de aplicação dos conhecimentos teóricos em situação real de vida e trabalho [...]”.

Nessa mesma direção, Bianchi, Alvarenga e Bianchi (2011) explanam que o estágio é constituído por experiências e estudos contínuos, com a finalidade de formar profissionais aptos para ingressar no mercado de trabalho. Nessa mesma perspectiva, Bianchi, Alvarenga e Bianchi (2003, p. 14) afirmam que o objetivo principal do estágio supervisionado é "enviar ao mercado de trabalho estudantes aptos a alcançar um bom aprendizado em sua permanência na empresa e egressos competentes em sua profissão".

Portela e Schumacher (2007) ressalvam que é importante pensar no campo de estágio não apenas para cumprir com as horas exigidas pelo curso, mas sim, para apresentar soluções e melhorias aos possíveis problemas que possam surgir ou, até mesmo, contribuir para ações existentes dentro da empresa que concedeu o estágio. Essa contribuição, oferece benefícios não apenas para a empresa concedente, mas também, para o próprio estagiário que poderá ser efetivado futuramente como funcionário, caso tenha atingido um bom desempenho no decorrer do estágio.

O estágio supervisionado obrigatório é um período repleto de informações sobre o funcionamento do ambiente de trabalho, possibilita reflexões a respeito da maneira de agir, além de incluir conhecimentos e análises do campo de estágio, uma vez que, o estagiário passará a conhecer a empresa e os tipos de atividades a serem desenvolvidas. A Instituição de Ensino também será beneficiada com as informações positivas sobre a atuação dos estagiários na empresa concedente. Por sua vez, a empresa que ofereceu a oportunidade de estágio, terá sua recompensa, pois, essa chance oferecida, permitirá uma nova possibilidade de mudanças

Revista Expectativa, Toledo/PR, v.20, n. 3, p. 108-130, jul./set., 2021. 
positivas na organização, por meio do olhar do estagiário (PORTELA; SCHUMACHER, 2007).

Vale ressaltar que a possibilidade de estagiar está presente tanto nas instâncias públicas, quanto nas privadas e não governamentais. O papel das instituições de modo geral é oferecer aos futuros profissionais a oportunidade de adquirir experiência e aprendizado durante o período de estágio (PORTELA; SCHUMACHER, 2007). Esses autores acrescentam que as experiências vivenciadas pelos estagiários levam a uma reflexão sobre a decisão de continuar ou não na profissão escolhida. Ou seja, o estágio vai além da prática de atividades desenvolvidas, ele é também responsável pelo direcionamento do futuro profissional.

Portanto, esse período de aprendizado é relevante para o estagiário e para a empresa concedente, já que, haverá uma troca mútua de conhecimentos e experiências, que contemplam os objetivos de ambas as partes, conforme ilustrado no Quadro 1.

Quadro 1 - Objetivos do estágio supervisionado para o estagiário e para a empresa

\begin{tabular}{|c|c|}
\hline \multicolumn{2}{|c|}{ Objetivos do estágio supervisionado para o estagiário e para a empresa } \\
\hline Para o estagiário & Para a empresa \\
\hline Acelera sua formação profissional; & $\begin{array}{l}\text { Elevar o nível de escolaridade de suas } \\
\text { equipes; }\end{array}$ \\
\hline $\begin{array}{l}\text { Possibilita a aplicação prática dos conhecimentos obtidos nas } \\
\text { disciplinas; }\end{array}$ & $\begin{array}{l}\text { Facilitar a entrada de novos conhecimentos e } \\
\text { técnicas de produção e serviços; }\end{array}$ \\
\hline $\begin{array}{l}\text { Motiva o estudo, pois, o estudante percebe a finalidade de } \\
\text { aplicação do aprendizado e sente suas possibilidades; }\end{array}$ & $\begin{array}{l}\text { Desenvolver soluções } \\
\text { problemas verificados; }\end{array}$ \\
\hline Permite maior assimilação das matérias de estudo; & Facilita a resolução de problemas; \\
\hline $\begin{array}{l}\text { Facilita e antecipa a definição da futura profissão pelo } \\
\text { estudante; }\end{array}$ & Visualiza suas necessidades e carências; \\
\hline $\begin{array}{l}\text { Ameniza o impacto da passagem da vida estudantil para a } \\
\text { profissional; }\end{array}$ & Melhora sua organização interna; \\
\hline $\begin{array}{l}\text { Possibilita perceber as próprias deficiências e buscar o } \\
\text { aprimoramento; }\end{array}$ & $\begin{array}{l}\text { Possibilita perceber as próprias deficiências e } \\
\text { buscar o aprimoramento; }\end{array}$ \\
\hline $\begin{array}{l}\text { Permite adquirir uma atitude de trabalho sistematizado, } \\
\text { desenvolvendo a consciência de produtividade; }\end{array}$ & Aumenta a produtividade e a organização; \\
\hline Propicia melhor relacionamento humano; & Propicia melhor relacionamento humano; \\
\hline $\begin{array}{l}\text { Incentiva a observação e a comunicação de ideias e } \\
\text { experiências, através dos relatórios elaborados; }\end{array}$ & Registra procedimentos e experiências. \\
\hline Incentiva o exercício do senso crítico; & Pode contar com equipe interdisciplinar. \\
\hline $\begin{array}{l}\text { Compreende as diretrizes, a organização e o funcionamento } \\
\text { das empresas e instituições, em geral. }\end{array}$ & - \\
\hline
\end{tabular}

Fonte: Portela e Schumacher (2007, p. 37).

Com base no Quadro 1, é possível perceber os inúmeros benefícios que o estágio supervisionado proporciona para o estagiário e para a empresa que oferece a oportunidade desse

Revista Expectativa, Toledo/PR, v.20, n. 3, p. 108-130, jul./set., 2021. 
aprendizado. Pode-se dizer que é por meio do estágio que o aluno tem seu primeiro contato com a profissão que ele pretende exercer após concluir os estudos e dessa forma colocar em prática os conhecimentos teóricos estudados ao longo do curso e, ao mesmo tempo, aperfeiçoar as atribuições que lhe são designadas e supervisionadas pela empresa concedente, juntamente com a Universidade.

Percebe-se que o estágio prepara o aluno não apenas para a vida profissional, mas também, para a vida pessoal, visto que possibilita experiências que são adquiridas e aprimoradas pela amplitude dos conhecimentos que permeiam os âmbitos técnicos, sociais, científicos e culturais. Assim, a finalidade do estágio visa possibilitar a preparação do aluno para o exercício profissional mediante o aprendizado acumulado no campo de estágio. Cabe ao estagiário procurar aproveitar as experiências e conhecimentos adquiridos durante essa fase para que possa desempenhar sua profissão com maior segurança e competência (PORTELA; SCHUMACHER, 2007).

\subsection{A REGULAMENTAÇÃO DO ESTÁGIO SUPERVISIONADO NO BRASIL}

No Brasil o estágio é regulamentado pela Lei 11.788/08, criada em 25 de setembro de 2008, cuja finalidade é assegurar o aluno estagiário, a Instituição de Ensino e a empresa concedente durante o processo de aprendizagem.

\footnotetext{
Art. 1ํㅡㄹ Estágio é ato educativo escolar supervisionado, desenvolvido no ambiente de trabalho, que visa à preparação para o trabalho produtivo de educandos que estejam frequentando o ensino regular em instituições de educação superior, de educação profissional, de ensino médio, da educação especial e dos anos finais do ensino fundamental, na modalidade profissional da educação de jovens e adultos.
}

Conforme estabelece o art. $1^{\circ}$ da já citada Lei, o estágio é compreendido como um ato educativo escolar que precisa ter um acompanhamento de um supervisor para orientar as atividades desenvolvidas pelo estagiário em seu local de estágio, visando à preparação do educando para o mercado de trabalho.

A parte concedente deve dispor de um local adequado para a realização do estágio, além de propor atividades que complementem o aprendizado do estagiário, oferecer um seguro contra acidentes pessoais, comprovar relação de estágio por meio de documentos e manter a Instituição

Revista Expectativa, Toledo/PR, v.20, n. 3, p. 108-130, jul./set., 2021. 
de Ensino informada sobre o andamento do estágio por meio de relatórios semestrais (BRASIL, 2008). A Instituição de Ensino, dever celebrar termo de compromisso com as partes envolvidas no processo, avaliar as instalações da parte concedente e indicar professor para orientar o estagiário durante a sua prática (BRASIL, 2008).

Essas exigências asseguradas pela regulamentação do estágio supervisionado são de suma relevância para o desenvolvimento do aprendizado do aluno, além de evitar problemas futuros entre o estagiário, a Instituição de Ensino e a empresa concedente.

\title{
2.2 A REGULAMENTAÇÃO DO ESTÁGIO SUPERVISIONADO NO CURSO DE SECRETARIADO EXECUTIVO BILÍNGUE DA UFPB
}

O anexo I da Resolução no 41/2006 do CONSEPE/UFPB, que aprova o Projeto Político Pedagógico do Curso de Secretariado Executivo Bilíngue, assegura que o objetivo do curso é formar bacharéis com competências para promover e participar da melhoria do processo de gestão e desenvolvimento das organizações públicas e privadas, na busca do aumento de produtividade e competitividade e aptos a atuar no mercado altamente competitivo e em constantes transformações como: assessor executivo, gestor, consultor e empreendedor e tradutor. Este documento ainda especifica cada uma dessas funções gerenciais da seguinte forma:

\begin{abstract}
Assessor - atendendo a executivos, utilizando-se das técnicas secretariais, e como conhecedor de tecnologia de informação, arquivística e documentação, ética, comunicação e redação empresarial; Gestor - desenvolvendo funções gerenciais com qualidade no sentido de otimizar a produtividade do campo onde atua; Empreendedor - buscando ideias e práticas inovadoras, no sentido do desenvolvimento de uma gestão estratégica, capaz de transformar ameaças em oportunidades; Consultor - trabalhando com a cultura de organização, realizando mudanças em grupo com a finalidade de atingir os objetivos da organização e dos executivos; Tradutor - realizando traduções de espanhol e inglês facilitando a gestão e articulações a nível nacional e internacional (UFPB, p. 6, 2006).
\end{abstract}

Percebe-se que cada função gerencial apresentada possibilita ao profissional de secretariado executivo bilíngue formas de atuação diversificadas. Além de permitir que ele faça escolha em qual dessas dessas funções ele pretende se aperfeiçoar. Ressaltando que o objetivo do curso é que ele transite por cada uma dessas funções.

O estágio no curso de Secretariado Executivo Bilíngue é regulamentado pela resolução 01/2009 e os objetivos são:

Revista Expectativa, Toledo/PR, v.20, n. 3, p. 108-130, jul./set., 2021. 
Art. $2^{\circ}$ São objetivos do estágio do Curso de Secretariado Executivo:

I - Proporcionar experiências práticas ao aluno, utilizando os conhecimentos obtidos durante o curso e em outras situações, a fim de aprimorá-los, após testá-los; II - Desenvolver as habilidades e competências para o exercício da profissão;

III - Refletir sobre o fazer profissional do bacharel em Secretariado Executivo Bilíngue, bem como estimular o aperfeiçoamento pessoal e profissional (UFPB, p. 8, 2009).

Como pode-se observar, os principais objetivos do estágio no curso de Secretariado Executivo Bilíngue são garantir ao estagiário o aprimoramento de todos os conhecimentos absorvidos na sala de aula e no campo de estágio, oportunizar o desenvolvimento de suas habilidades e competências e promover uma reflexão acerca do seu fazer profissional após sua formação.

É notório que tanto no objetivo do curso quanto no do estágio tem-se a finalidade de preparar o estudante de secretariado executivo bilíngue para a vida profissional, possibilitando a este, no momento de sua atuação, estar apto a atuar com competência em todas as cinco funções gerenciais supracitadas. O curso contribui com as teorias, enquanto o estágio supervisionado dispõe das ferramentas que consolida sua formação.

\subsection{A ATUAÇÃO DO SECRETÁRIO EXECUTIVO NO MERCADO DE TRABALHO}

Na opinião de Lima e Cantarotti (2010), a atuação do profissional de secretariado executivo bilíngue nos dias atuais, têm um papel relevante no âmbito organizacional, quando comparada às décadas de 1950 e 1960, Tendo em vista que, anteriormente era visto como um profissional que se restringia a executar ordens. A medida em que foram ocorrendo transformações nos perfis organizacionais, também ocorreram transformações significativas na sua forma de atuar, trazendo como benefício a valorização dessa profissão.

Lima e Cantarotti (2010) acrescentam que essas transformações no perfil do profissional de secretário executivo, foram relevantes não apenas para a profissão, mas também para sua atuação dentro das organizações, uma vez que ele pode ocupar cargo gerencial, diferente do que era há décadas, em que sua função era apenas operacional.

Bianchi, Alvarenga e Bianchi (2003) reafirmam que atualmente o profissional de secretariado executivo tem se destacado significativamente, em decorrência de suas possíveis

Revista Expectativa, Toledo/PR, v.20, n. 3, p. 108-130, jul./set., 2021. 
áreas de atuação, devido sua aptidão em trabalhar de maneira eficiente, seja em organizações de pequeno, médio ou de grande porte.

Com isso, as exigências feitas a esses profissionais têm aumentado constantemente, principalmente com relação ao sigilo, uma vez que eles exercem funções de extrema confiança dentro das organizações, principalmente, quando se trata de cargos que necessitam de maior discrição (BIANCHI; ALVARENGA; BIANCHI, 2003).

Nessa mesma perspectiva, Netto (2013) afirma que as funções delegadas a esses profissionais passaram a ser de maior responsabilidade, pois, eles tiveram que lidar com assuntos relevantes e sigilosos que se divulgados, podem comprometer não só a empresa, mas a sua reputação. É exigido desse profissional, além de suas qualificações, o comprometimento com a empresa e o sigilo profissional.

O secretário executivo precisa ser além de hábil e competente, um profissional em que a organização possa confiar. São essas qualidades que permitem o maior desempenho na execução de suas atividades. Tendo em vista que as organizações estão em busca de profissionais confiáveis, qualificados e preparados para enfrentar a nova realidade imposta pelo mercado de trabalho (NETTO, 2013).

Assim, compete ao secretário executivo como agente facilitador, priorizar a busca por resultados, gerir informações, prestar assessoramento de maneira estratégica e inovadora, a fim de colaborar com seu executivo, tanto no ganho do tempo, quanto na facilitação do andamento dos processos organizacionais, conforme comenta Netto, (2013).

Nos tópicos a seguir, discorre-se especificamente sobre assessoria, consultoria, gestão e empreendedorismo.

\subsection{ASSESSORIA}

Nonato (2009) retrata que o ato de assessorar surgiu nos primórdios da humanidade, advindo da ajuda mútua entre os homens, por meio do processo de organização, seleção, assistência e encaminhamento de documentos tidos como fontes do saber. O autor caracteriza a assessoria como sendo uma área em que se produz o conhecimento de forma coletiva.

De acordo com Paes et al. (2015) a assessoria é tida como a principal função desenvolvida pelo profissional de secretariado executivo no âmbito de uma organização, visto

Revista Expectativa, Toledo/PR, v.20, n. 3, p. 108-130, jul./set., 2021. 
que é uma prática presente no seu dia a dia. Este assessoramento contribui para o andamento dos processos diários dentro das organizações públicas ou privadas, visando garantir resultados positivos por meio da coletividade.

Para se inserir no meio organizacional como um assessor, o profissional de Secretariado Executivo deve comprovar um conjunto de conhecimentos, como os técnicos, culturais e uma bagagem comportamental, provando estar habilitado para assessorar os mais diferentes tipos de chefias, nas mais diversas organizações, tanto públicas como privadas (FERREIRA, 2011, p. 42).

O profissional de secretariado executivo precisa provar que ele está apto a desenvolver atividades que envolvam o domínio das técnicas secretariais, boa comunicação, desenvolver o espírito de liderança e, acima de tudo, ser ético. Por conseguinte, possibilitará o assessoramento nos mais diversos tipos de organizações, colaborando com diversos perfis de chefia (FERREIRA, 2011). Em outras palavras, o assessor busca agir no ambiente de trabalho solucionando os mais diversos problemas.

\title{
2.5 CONSULTORIA
}

De acordo com Crocco e Guttmnann (2010, p. 8) consultoria representa:

\begin{abstract}
Um processo interativo, executado por uma ou mais pessoas, independentes e externas ao problema em análise, com o objetivo de fornecer aos executivos da empresa-cliente um ou mais conjuntos de opções de mudanças que proporcionem a tomada de decisão mais adequada ao atendimento das necessidades da organização.
\end{abstract}

Segundo Paes et al. (2015) cabe ao consultor aconselhar e apresentar soluções para os clientes que o procuram, uma vez que compete a ele, como conhecedor de determinados assuntos, estar apto a solucionar os possíveis problemas, já que é exigido dele competência técnica e habilidades para a área específica de sua atuação. "Consultor é a pessoa que tem certa influência sobre um indivíduo, um grupo ou uma organização, mas não tem poder direto para efetuar mudanças ou implementar programas [...]” (BLOCK, 2013, p. 36).

Portela e Schumacher (2009) afirmam que o consultor é de fato o responsável por apresentar soluções e melhorias devido sua capacidade analítica e perceptiva. Mas, não têm autonomia para promover mudanças ou revoluções em seu local de trabalho. Seu papel é estudar a empresa e seus clientes, trançando um diagnóstico com base nos dados analisados.

Revista Expectativa, Toledo/PR, v.20, n. 3, p. 108-130, jul./set., 2021. 
No que tange as atividades do consultor, Ferreira (2011, p. 46) revela as seguintes atividades desenvolvidas pelo profissional de secretariado executivo bilíngue são:

Organizações de reuniões (suporte e assessoramento); intermediação de clientes e contatos; elaboração e editoração de textos técnicos; consultoria em organização do trabalho, utilizando da O\&M (organização e métodos); organização de viagens, de eventos e de arquivos; palestras, treinamentos e cursos.

Mediante o exposto, observa-se que o consultor pode ser um diferencial dentro das organizações, uma vez que seu papel é propor mudanças em conjunto, a fim de alcançar resultados que contribuam para o melhoramento nas tomadas de decisões da organização; além de compreender o funcionamento da empresa, conhecer seus clientes, promover um bom relacionamento entre a organização e o cliente, estar atento aos problemas que possam surgir e apresentar soluções e melhorias que gerem algum tipo de benefícios, de forma a contribuir para o alcance dos objetivos esperados pelos envolvidos.

\subsection{GESTÃO}

Portela e Schumacher (2009) ressaltam que houve mudanças no gerenciamento secretarial, antes o secretário executivo era responsável por realizar apenas as atividades que lhe eram confiadas, diferente dos dias atuais, visto que ele além de gerir informações, passou a fazer parte dos processos decisórios.

Essas mudanças contribuíram para a valorização e desenvolvimento de um novo perfil dos secretários executivos dentro das organizações, em que esse profissional deixou para trás o simples ato de executar tarefas, para gerir e refletir sobre suas tomadas de decisões (PORTELA; SCHUMACHER, 2009).

As atividades desenvolvidas pelo profissional de secretariado executivo na área da gestão, são aquelas que precisam de planejamento, organização, direção e controle, na tentativa de evitar conflitos, otimizar os resultados e garantir o bom desempenho dentro das organizações (AZEVEDO; COSTA, 2006). Observa-se que o secretário executivo é um profissional participativo, proativo, tomador de decisões, empenhado em contribuir com o crescimento e desenvolvimento dentro de qualquer organização, com capacidade de planejar, organizar, dirigir e controlar, e não mais exercendo uma função que apenas, cumpra o que se pede.

Revista Expectativa, Toledo/PR, v.20, n. 3, p. 108-130, jul./set., 2021. 


\subsection{EMPREENDEDORISMO}

Dornelas (2014, p. 28) afirma que "Empreendedorismo é o envolvimento de pessoas e processos que, em conjunto, levam à transformação de ideias em oportunidades. E a perfeita implementação destas oportunidades leva à criação de negócios de sucesso". O autor acrescenta que o empreendedor é aquele que ao perceber uma oportunidade, não hesita em aproveitá-la da melhor forma. E através dela criar algo novo e lucrativo, por meio da utilização dos recursos necessários, tendo o cuidado de só assumir riscos calculados.

Para Neiva e D' Elia (2009) o empreendedorismo foi acrescentado às novas competências do secretário executivo, visto que, o papel do empreendedor é fazer a diferença frente a competitividade e estar sempre atento as oportunidades. Este agente é responsável pelo planejamento, organização, transformação e inovação. As autoras supracitadas ressaltam que não existe um manual que o profissional siga para se tornar um empreendedor, e sim, que há indicadores. Essas evidências são responsáveis por moldar o perfil realizador, uma vez que o ato de empreender é uma competência desenvolvida por meio de uma iniciativa. "O talento empreendedor resulta da percepção, direção, dedicação e de muito trabalho dessas pessoas especiais, que fazem acontecer. Onde existe esse talento, há a oportunidade de crescer, diversificar e desenvolver novos negócios” (DORNELAS, 2014, p. 32).

Nessa mesma perspectiva, Ferreira (2011) caracteriza as atividades de empreendedorismo desenvolvidas pelo profissional de secretariado executivo, como aquelas que envolvem iniciativa, ideias, determinação, reflexões, sugestões, proatividade, participação, e práticas consideradas inovadoras, visando sempre a busca por resultados positivos e satisfatórios para as organizações. São perceptíveis as possibilidades de atuação que a profissão de Secretariado Executivo Bilíngue permite aos profissionais, com base nas funções gerenciais apresentadas.

\section{PERCURSO METODOLÓGICO}

Esta pesquisa caracteriza-se como exploratória, que para Gil (2008, p. 27) a característica exploratória é desenvolvida [...] com o objetivo de proporcionar visão geral, de tipo aproximativo, acerca de determinado fato".

Revista Expectativa, Toledo/PR, v.20, n. 3, p. 108-130, jul./set., 2021. 
Para atender aos objetivos propostos, o estudo foi conduzido sob a abordagem quantitativa e qualitativa. Segundo Richardson (2010) a abordagem qualitativa tem como propósito compreender de maneira detalhada o objeto de estudo utilizado pelo pesquisador e obter a resposta da questão de pesquisa, já a quantitativa permite desenvolver uma explicação mais geral do fenômeno.

Esta investigação caracteriza-se também como pesquisa do tipo documental, ou de análise de material escrito já publicado. Conforme explicam Prodanov e Freitas (2013, p. 55), a pesquisa documental parte de "materiais que não receberam ainda um tratamento analítico ou que podem ser reelaborados de acordo com os objetivos da pesquisa”, o que inclui os relatórios de estágio adotados como corpus deste estudo.

Para ter acesso aos relatórios que fazem parte do estudo foi solicitada autorização prévia à coordenadora de estágio do referido Curso, mediante isso, realizou-se a coleta dos dados no período de 27 a 31 de agosto de 2018, seguindo a seguinte ordem: identificação das pastas, mapeamento das atividades de estágio e identificação das empresas concedentes. Foram catalogados 104 (cento e quatro) relatórios referentes as disciplinas de estágio supervisionados II, III e IV produzidos por alunos matriculados nos semestres de 2017.1 e 2017.2. Vale ressaltar que esse recorte, dos dois últimos semestres, se justifica pela viabilidade da pesquisa.

Como mecanismo de seleção, optou-se pela delimitação de uma temática específica: Assessoria, consultoria, gestão, empreendedorismo e tradução. A partir dessa delimitação observou-se as atividades descritas nos relatórios, conforme análise a seguir.

\section{ANÁLISE E DISCUSSÃO}

Após a coleta de dados, foi possível identificar quais eram as atividades desenvolvidas pelos estagiários, nos estágios II, III e IV, nos semestres 2017.1 e 2017.2. Tais atividades foram separadas de acordo com as funções gerenciais que as pertencem. As funções são: assessoria, consultoria, empreendedorismo, gestão e tradução. Supracitadas no referencial teórico, de acordo com o projeto pedagógico do curso. No que tange a tradução, não foi encontrado autores que abordem essa função gerencial.

O Quadro 2, a seguir, apresenta o mapeamento das atividades desenvolvidas pelos sujeitos da pesquisa na disciplina de Estágio Supervisionado II, III e IV durante o semestre de 2017.1.

Revista Expectativa, Toledo/PR, v.20, n. 3, p. 108-130, jul./set., 2021. 
Quadro 2 - Atividades desenvolvidas pelos estagiários no semestre 2017.1

\begin{tabular}{|c|c|c|c|}
\hline Funções gerenciais & $\begin{array}{c}\text { Atividades do Estágio } \\
\text { Supervisionado II }\end{array}$ & $\begin{array}{c}\text { Atividades do Estágio } \\
\text { Supervisionado III }\end{array}$ & $\begin{array}{c}\text { Atividades do Estágio } \\
\text { Supervisionado IV }\end{array}$ \\
\hline Assessoria & $\begin{array}{ll}\text { - } & \text { Agendamento; } \\
\text { - } & \text { Atendimento ao } \\
& \text { público (interno e } \\
& \text { externo); } \\
\text { - } & \text { Atendimento } \\
& \text { telefônico; } \\
\text { - } & \text { Redação de atas; } \\
\text { - } & \text { Produção de } \\
\text { documentos; } \\
\text { - } & \text { Criação de pastas } \\
\text { (físicas e virtuais); } \\
\text { - } & \text { Criação de tabelas; } \\
\text { - } & \text { Rotinas } \\
& \text { administrativas. } \\
\text { - } & \text { Acompanhamento de } \\
& \text { reunião; }\end{array}$ & 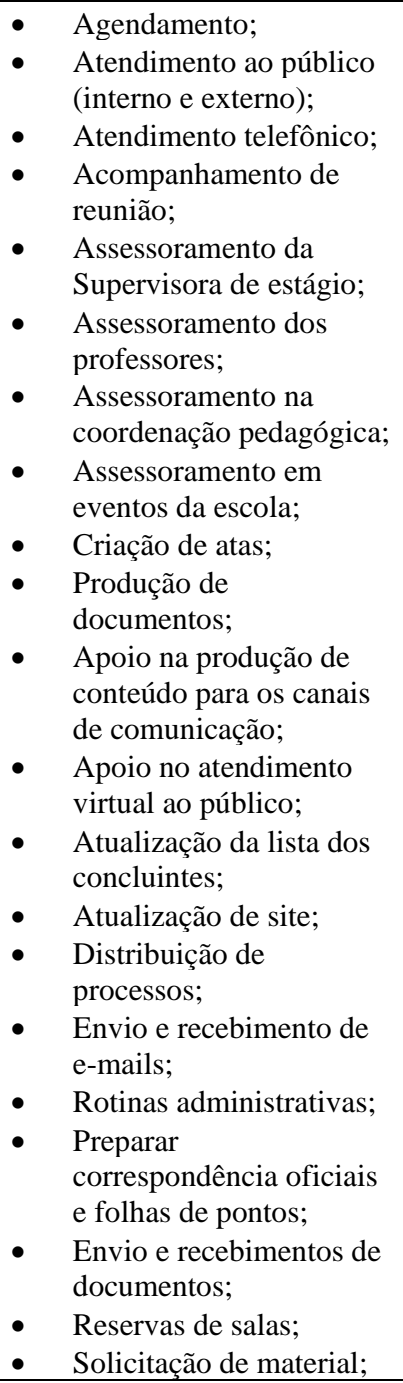 & $\begin{array}{ll}\text { - } & \text { Agendamento; } \\
\text { - } & \text { ptendimento ao } \\
& \text { público (interno e } \\
\text { externo); } & \text { Atendimento } \\
\text { - } & \text { telefônico; } \\
\text { - Acompanhamento de } \\
\text { reunião; } \\
\text { - Assessoramento a } \\
\text { - } \quad \text { Asseressoria; } \\
\text { gerente; } \\
\text { Assessoramento ao } \\
\text { gestor; } \\
\text { Assessoria a imagem e } \\
\text { relações públicas da } \\
\text { coordenação de TCC; } \\
\text { Assessoria em eventos; } \\
\text { - Criação de atas; } \\
\text { Produção de } \\
\text { documentos; } \\
\text { Atualização de dados } \\
\text { dos estudantes; } \\
\text { Envio e recebimento } \\
\text { de correspondência } \\
\text { eletrônica; } \\
\text { Reserva de espaço; } \\
\end{array}$ \\
\hline Consultoria & $\begin{array}{ll}\text { - } & \text { Organização de } \\
\text { arquivos; } \\
\text { Organização de } \\
\text { armário } \\
\text { Organização de } \\
\text { documentos; } \\
\text { Organização do } \\
\text { ambiente de trabalho. }\end{array}$ & $\begin{array}{ll}\text { - } & \text { Organização de } \\
\text { arquivos; } \\
\text { - } & \text { Organização de } \\
\text { armários; }\end{array}$ & $\begin{array}{ll}\text { - } & \text { Organização de } \\
\text { arquivos; } \\
\text { - } \\
\text { Organização do } \\
\text { ambiente de trabalho; } \\
\text { - Assessoria a imagem e } \\
\text { relações públicas da } \\
\text { coordenação de TCC; } \\
\text { - Assessoria em eventos; } \\
\text { - } \quad \text { Conscientização do } \\
\text { patrimônio público; } \\
\text { Relacionamento } \\
\text { interpessoal. }\end{array}$ \\
\hline
\end{tabular}

Revista Expectativa, Toledo/PR, v.20, n. 3, p. 108-130, jul./set., 2021. 


\begin{tabular}{|c|c|c|c|}
\hline & & $\begin{array}{ll}\text { administrativos e } \\
\text { contratos; } \\
\text { - Trabalho; } \\
\text { - } \quad \text { Orientar clientes e } \\
\text { visitantes. } \\
\end{array}$ & \\
\hline Gestão & $\begin{array}{ll}\text { - } & \text { Controle de ponto de } \\
\text { - } & \text { Cuncionário; } \\
& \text { entradenação saída de } \\
& \text { documentos; } \\
\text { - } & \text { Controle de E-mail; } \\
\text { - } & \text { Gerir informações; }\end{array}$ & $\begin{array}{ll}\text { - } & \text { Conferir despacho e } \\
\text { entrega de materiais; } \\
\text { - } & \text { Controle processual; } \\
\text { - } & \text { Gestão de documentos; } \\
\text { - } & \text { Gerir informações; } \\
\text { - } & \text { Coordenar entradas e } \\
& \text { saídas de documentos e } \\
\text { processos; } \\
\text { - } \\
\text { Gerenciamento dos } \\
\text { meios de comunicação. }\end{array}$ & $\begin{array}{ll}\text { - } & \text { Controle financeiro; } \\
\text { - } & \text { Controle das chaves; } \\
\text { - } & \text { Gestão de dados. } \\
\text { - } & \text { Gerir informações. }\end{array}$ \\
\hline Empreendedorismo & Sem registros & Sem registros & Sem registros \\
\hline Tradução & Sem registros & Sem registros & Sem registros \\
\hline
\end{tabular}

Fonte: Dados da pesquisa (2018).

Conforme apresentado no Quadro 2, observa-se que nas três disciplinas de estágio, os estudantes desenvolveram atividades práticas voltadas para assessoria, consultoria e gestão. Já as funções relativas ao empreendedorismo e tradução não foram identificadas em nenhuma das disciplinas de estágio investigadas nos relatórios do semestre de 2017.1.

No estágio II, percebe-se (9) tipos de atividades voltada para assessoria, (4) para consultoria e (4) na gestão. No estágio supervisionado III, foram identificadas (21) tipos de atividades na assessoria, (11) na consultoria e (6) na gestão. Por último, no estágio supervisionado IV, identifica-se (12) tipos de atividades na assessoria, (6) na consultoria, e (5) na gestão. Assim, os dados permitem afirmar que os estagiários do curso de Secretariado Executivo Bilíngue da UFPB, durante o semestre citado, não obtiveram experiência prática no campo do empreendedorismo e da tradução.

A pesquisa ainda revela que as atividades realizadas no estágio supervisionado II se repetem nas disciplinas de III e IV, a exemplo do agendamento, atendimento ao público e atendimento telefônico. O Gráfico 1, apresenta o percentual de todas as atividades desenvolvidas durante os estágios supervisionado II, III e IV no semestre 2017.1. 
Estágio supervisionado obrigatório: atividades desenvolvidas pelos discentes do curso de Secretariado Executivo Bilíngue da UFPB

Gráfico 1 - Atividades desenvolvidas nos estágios supervisionados II, III e IV no semestre 2017.1

Tradução

Gestão

$19,2 \%$

Empreendedorismo

Consultoria

$26,9 \%$

Assessoria

Fonte: Dados de pesquisa (2018).

Conforme apresentado no Gráfico 1, percebe-se que em primeiro lugar se destacam as atividades voltadas para assessoria, seguida da consultoria com mais de $20 \%$ e, por último, aquelas do campo da gestão, representando 19,2\%.

O Quadro 3, a seguir, apresenta o mapeamento das atividades desenvolvidas pelos sujeitos da pesquisa nas disciplinas de Estágio Supervisionado II, III e IV, durante o semestre de 2017.2.

Quadro 3 - Atividades desenvolvidas pelos estagiários no semestre 2017.2

\begin{tabular}{|c|c|c|c|}
\hline Funções gerenciais & $\begin{array}{c}\text { Atividades do Estágio } \\
\text { supervisionado II }\end{array}$ & $\begin{array}{c}\text { Atividades do Estágio } \\
\text { Supervisionado III }\end{array}$ & $\begin{array}{l}\text { Atividades do Estágio } \\
\text { Supervisionado IV }\end{array}$ \\
\hline Assessoria & $\begin{array}{ll}\text { - } & \text { Atendimento ao público } \\
\text { externo e interno; } \\
\text { - } \\
\text { Produção de } \\
\text { documentos; } \\
\text { - } \quad \text { Encaminhamento de } \\
\text { protocolo. } \\
\text { - Assessoramento do } \\
\text { Secretário. }\end{array}$ & $\begin{array}{ll}\text { - } & \text { Atendimento ao público } \\
\text { (interno e externo); } \\
\text { - } \\
\text { Produção de } \\
\text { - } \quad \text { Abertura e } \\
\text { encaminhamento de } \\
\text { processos; } \\
\text { - Assessoramento do } \\
\text { presidente da } \\
\text { Associação; } \\
\text { Informação sobre o } \\
\text { material disponível na } \\
\text { Biblioteca; } \\
\text { - Orientação das normas } \\
\text { de funcionamento da } \\
\text { Biblioteca; } \\
\text { Envio de } \\
\text { - correspondência; } \\
\text { Envio de e-mails; } \\
\text { Preenchimento de dados } \\
\text { em planilhas; } \\
\text { Preenchimento de } \\
\text { certificados; } \\
\text { Realização de cadastro } \\
\text { dos usuários no SIGAA; } \\
\text { Rotinas administrativas; }\end{array}$ & 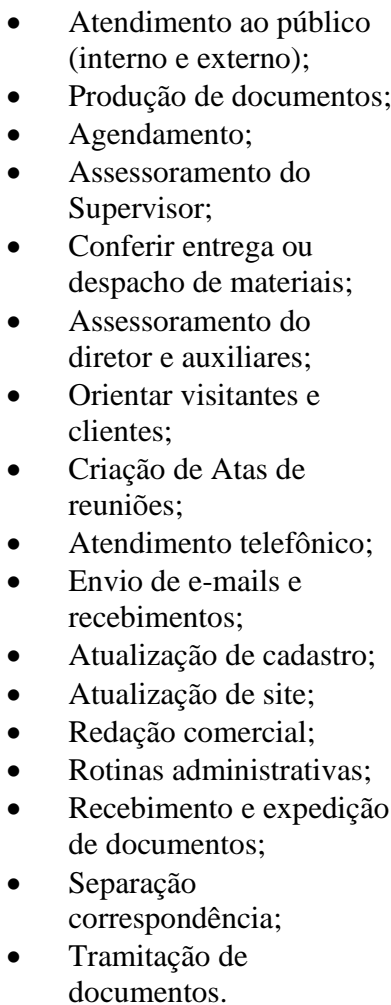 \\
\hline
\end{tabular}

Revista Expectativa, Toledo/PR, v.20, n. 3, p. 108-130, jul./set., 2021. 
Estágio supervisionado obrigatório: atividades desenvolvidas pelos discentes do curso de Secretariado Executivo Bilíngue da UFPB

\begin{tabular}{|c|c|c|c|}
\hline & & $\begin{array}{ll}\text { - } & \text { Entrega de } \\
\text { correspondências } \\
\text { institucionais. }\end{array}$ & \\
\hline Consultoria & $\begin{array}{l}\text { - } \quad \text { Organização de arquivos; } \\
\text { - } \quad \text { Organização de } \\
\text { ambiente; } \\
\text { - Organização de } \\
\text { armários; } \\
\text { - Organização de eventos } \\
\text { institucional. }\end{array}$ & $\begin{array}{ll} & \text { Organização de } \\
\text { - } & \text { Orquivos; } \\
& \text { Organização de } \\
\text { - } & \text { Orbiente; } \\
\text { - } & \text { Organização de eventos; } \\
& \text { documentos; } \\
\text { - } & \text { Organização de } \\
& \text { reuniões; } \\
\text { - } & \text { Organização de viagens. }\end{array}$ & $\begin{array}{ll}\text { - } & \text { Consultas no sistema; } \\
\text { - } & \text { Organização de arquivos; } \\
\text { - } & \text { Organização de } \\
& \text { ambiente; } \\
\text { - } & \text { Organização dos } \\
& \text { armários; } \\
\text { - } & \text { Organização de } \\
& \text { documentos; } \\
\text { - } & \text { Organização de eventos; } \\
\text { - } & \text { Organização de reuniões; }\end{array}$ \\
\hline Gestão & $\begin{array}{l}\text { Gerenciamento de } \\
\text { documentos. }\end{array}$ & $\begin{array}{l}\text { Controle de pessoal; } \\
\text { - Gestão dos quadros } \\
\text { escolares. }\end{array}$ & $\begin{array}{ll}\text { - } & \text { Controle de entrada e } \\
& \text { saída de processos; } \\
\text { - } & \text { Controle processual; } \\
\text { - } & \text { Gerenciamento dos meios } \\
& \text { de comunicação; } \\
\text { - } & \text { Gestão de documentos; } \\
\text { - } & \text { Gestão de memorando } \\
& \text { eletrônicos. } \\
\end{array}$ \\
\hline Empreendedorismo & $\begin{array}{l}\text { - Conseguiu modificar o } \\
\text { layout do ambiente; } \\
\text { Conseguiu objetos que } \\
\text { facilitassem o seu } \\
\text { trabalho. }\end{array}$ & Sem registros & Sem registros \\
\hline Tradução & Sem registros & Sem registros & Sem registros \\
\hline
\end{tabular}

Fonte: Dados da pesquisa.

Continuando as análises, os dados do Quadro 2 revelam que no semestre de 2017.2 os estagiários além de terem desenvolvido atividades práticas nos campos da assessoria, consultoria e gestão, também tiveram a oportunidade de praticar o campo do empreendedorismo. No entanto, similar ao que ocorreu no semestre anterior, apresentado no Quadro 1, a tradução não aparece nos relatórios do semestre de 2017.2.

Os dados revelam (4) atividades voltadas para assessoria, (4) para consultoria, (2) de empreendedorismo e (1) na gestão. No estágio supervisionado III, percebe-se (13) tipos de atividades na assessoria, (6) na consultoria, e (2) na gestão. No estágio supervisionado IV, identifica-se (17) tipos de atividades na assessoria, (7) na consultoria e (5) na gestão. O Gráfico 2 apresenta o percentual das atividades desenvolvidas durante os estágios supervisionado II, III e IV no semestre 2017.2.

Revista Expectativa, Toledo/PR, v.20, n. 3, p. 108-130, jul./set., 2021. 
Estágio supervisionado obrigatório: atividades desenvolvidas pelos discentes do curso de Secretariado Executivo Bilíngue da UFPB

Gráfico 2 - Atividades desenvolvidas nos estágios supervisionado II, III e IV, no semestre 2017.2

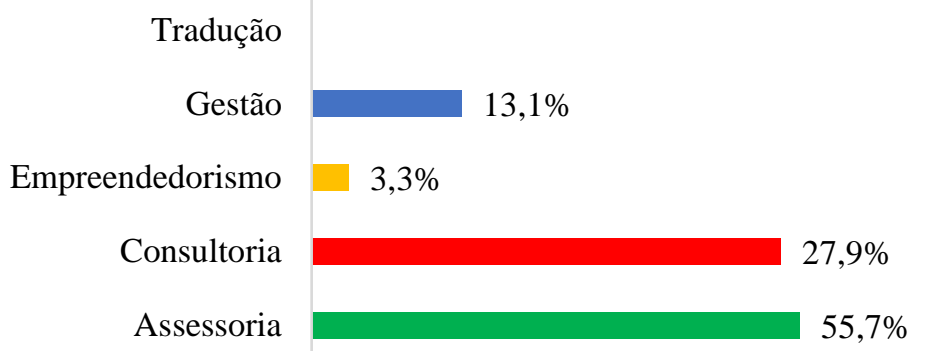

Fonte: Dados de pesquisa (2018).

Verifica-se no Gráfico 2, que a maior parte das atividades desenvolvidas pelos estágiários no semestre 2017.2 estão voltadas para assessoria, com o total de $55,7 \%$, na sequência tem-se a consultoria com $27,9 \%$, seguido da gestão com $13,1 \%$. Por último, aparece o empreendedorismo, com 3,3\%. Nesse semestre, os estagiários desenvolveram atividades no campo do empreendedorismo, o que não aconteceu no semestre 2071.1. Porém, os estagiários do curso não desenvolveram atividades de tradução. Percebe-se com base nos dados que a área de maior predominância no desenvolvimento das atividades nos estágios supervisionados estão na assessoria, seguida da consultoria, nos dois semestres investigados.

O Quadro 4, apresenta as empresas que concederam os Estágios Supervisionado II, III e IV, durante os semestres 2017.1 e 2017.2.

Quadro 4 - Empresas concedentes dos Estágios II, III e IV - 2017.1 e 2017.2

\begin{tabular}{|c|c|c|}
\hline Empresas/Organizações & Setores & Cidades \\
\hline Diocese de Guarabira & - $\quad$ Paróquia São Sebastião & Araçagi - PB \\
\hline $\begin{array}{l}\text { Escola Estadual de Ensino Médio Normal Francisco } \\
\text { Pessoa de Brito }\end{array}$ & - $\quad$ Secretaria & \\
\hline $\begin{array}{l}\text { Escola Estadual Indígena de Ensino Fundamental e } \\
\text { Médio Akajutibiró }\end{array}$ & - $\quad$ Secretaria & $\begin{array}{l}\text { Baia da Traição } \\
\text { - PB }\end{array}$ \\
\hline $\begin{array}{l}\text { Escola Municipal Professor Edgardo Júlio - } \\
\text { Guarabira - PB }\end{array}$ & - Secretaria, & \multirow[t]{2}{*}{ Guarabira - PB } \\
\hline $\begin{array}{l}\text { Escola Municipal Nazilda da Cunha Mora - } \\
\text { Guarabira - PB }\end{array}$ & - $\quad$ Secretaria & \\
\hline Escola de Ensino Fundamental Henrique de Almeida & - $\quad$ Secretaria & \multirow{3}{*}{$\begin{array}{l}\text { Itapororoca - } \\
\text { PB }\end{array}$} \\
\hline $\begin{array}{l}\text { Escola Estadual de Ensino Fundamental e Médio } \\
\text { Severino Félix de Brito }\end{array}$ & - $\quad$ Secretaria & \\
\hline Prefeitura Municipal de Itapororoca & $\begin{array}{ll}\text { - } & \text { Gabinete; } \\
\text { - } & \text { Secretaria da Agricultura. } \\
\end{array}$ & \\
\hline Escola de Ensino Fundamental Castro Pinto & - $\quad$ Secretaria & \multirow[t]{2}{*}{ Jacaraú -PB } \\
\hline Escola Estadual de Ensino Médio Alzira Lisboa & - $\quad$ Secretaria & \\
\hline Instituto Federal da Paraíba & • $\quad$ Não informado & \multirow[b]{4}{*}{$\begin{array}{l}\text { João Pessoa - } \\
\text { PB }\end{array}$} \\
\hline Instituto Brasileiro de Estatística-IBGE & - $\quad$ Secretaria do Gabinete & \\
\hline $\begin{array}{l}\text { Superintendência Regional do Trabalho e Emprego na } \\
\text { Paraíba }\end{array}$ & • $\quad$ Não informado & \\
\hline Universidade Federal da Paraíba Campus I & $\begin{array}{l}\text { - } \quad \text { Contabilidade da Reitoria; } \\
\text { - } \quad \text { Reitoria; }\end{array}$ & \\
\hline
\end{tabular}

Revista Expectativa, Toledo/PR, v.20, n. 3, p. 108-130, jul./set., 2021. 
Estágio supervisionado obrigatório: atividades desenvolvidas pelos discentes do curso de Secretariado Executivo Bilíngue da UFPB

\begin{tabular}{|c|c|c|}
\hline & $\begin{array}{l}\text { - } \quad \text { Pró-Reitoria de Gestão de Pessoas - } \\
\text { PROGEP. }\end{array}$ & \\
\hline $\begin{array}{l}\text { Escola Municipal de Ensino infantil e Fundamental } \\
\text { Maria das Neves Lisboa de Matosestá Lagoa de } \\
\text { dentro - PB }\end{array}$ & - $\quad$ Secretaria & $\begin{array}{l}\text { Lagoa de } \\
\text { Dentro - PB }\end{array}$ \\
\hline $\begin{array}{l}\text { Agrocamp Serviços e Consultoria em Atividades } \\
\text { Agrícolas e Pecuária }\end{array}$ & • $\quad$ Não informado & \multirow{6}{*}{$\begin{array}{l}\text { Mamanguape - } \\
\text { PB }\end{array}$} \\
\hline Connect Comércio e Serviços de Internet Ltda. & - $\quad$ Escritório & \\
\hline $\begin{array}{l}\text { Escola Estadual do Ensino Fundamental Professor } \\
\text { Luiz Aprígio }\end{array}$ & - $\quad$ Secretaria & \\
\hline $\begin{array}{l}\text { Escola Estadual do Ensino Fundamental e Médio } \\
\text { Senador Rui Carneiro }\end{array}$ & - $\quad$ Secretaria & \\
\hline $\begin{array}{l}\text { Escola Estadual de Ensino Fundamental Umbelina } \\
\text { Garcez }\end{array}$ & - $\quad$ Secretaria & \\
\hline Fazenda Santa Terezinha Ltda. & - $\quad$ Escritório & \\
\hline Universidade Federal da Paraíba Campus IV & $\begin{array}{ll}\text { - } & \text { Biblioteca Central. } \\
\text { - } & \text { Biblioteca Setorial; } \\
\text { - } & \text { Coordenação de Letras em Língua } \\
& \text { Inglesa; } \\
\text { - } & \text { Coordenação de Letras em Língua; } \\
& \text { Espanhola; } \\
\text { - } \quad \text { Coordenação de Secretariado } & \text { Executivo Bilíngue; } \\
\text { - } \quad \text { Departamento de Ciências Sociais } \\
\text { - } \quad \text { Aplicadas (DCSA); } \\
\text { - } \quad \text { Laboratamento de Letras. } \\
\text { - } \quad \text { LAEL) de Estudos Linguísticos } \\
\text { - Secretariado } \\
\text { - Secretaria da Direção de Centro; } \\
\text { Subprefeitura } \\
\end{array}$ & \\
\hline 14 a Gerência Regional de Educação - GRE & • $\quad$ Não informado & \\
\hline $\begin{array}{l}\text { Escola Estadual Indígena de Ensino fundamental e } \\
\text { Médio Índio Pedro Máximo de Lima - Aldeia três } \\
\text { rios }\end{array}$ & - $\quad$ Secretaria & Marcação - PB \\
\hline $\begin{array}{l}\text { Escola Estadual de Ensino Fundamental e Médio } \\
\text { Pedro Poti }\end{array}$ & - $\quad$ Secretaria & Mataraca -PB \\
\hline $\begin{array}{l}\text { Cooperativa da Agroindústria da agricultura familiar } \\
\text { (CAAF/LNPB) }\end{array}$ & - $\quad$ Não informado & Pedro Regis - \\
\hline $\begin{array}{l}\text { Escola Estadual de Ensino infantil Fundamental e } \\
\text { Médio Margarida Dias }\end{array}$ & - $\quad$ Secretaria & $\mathrm{PB}$ \\
\hline $\begin{array}{l}\text { Centro comunitário beneficentes dos moradores de } \\
\text { Salema }\end{array}$ & - $\quad$ Contabilidade & \\
\hline Prefeitura Municipal de Rio Tinto & $\begin{array}{ll}- & \text { Gabinete } \\
\text { - } & \text { Setor de RH } \\
\end{array}$ & Rio Tinto - PB \\
\hline Universidade Federal da Paraíba Campus IV & $\begin{array}{ll}\text { - } & \text { Setor de Arquivo } \\
\text { - } & \text { Prefeitura } \\
\text { - } & \text { Subprefeitura } \\
\text { - } & \text { Arquivo setorial da Direção de centro. }\end{array}$ & \\
\hline
\end{tabular}

Fonte: Dados da pesquisa (2018).

De acordo com as informações obtidas no Quadro 4, destaca-se que um total de 30 (trinta) empresas/organizações receberam estágios do curso de Secretariado Executivo nos dois semestres investigados. Observa-se que um total de 15 escolas do Vale do Mamanguape

Revista Expectativa, Toledo/PR, v.20, n. 3, p. 108-130, jul./set., 2021. 
receberam estagiários nos semestres de 2017.1 e 2017.2 para desempenhar atividades nas secretarias. Esse dado é relevante, pois indica a abertura que a UFPB está tendo no âmbito estadual e municipal para inserir seus alunos durante a prática profissional. .

Percebe-se também que a UFPB, Campus de Mamanguape, se destaca com um total de (11) setores que ofertaram estágios, seguida pela unidade de Rio Tinto com (4) setores e essa mesma quantidade de oferta no Campus I da UFPB em João Pessoa-PB. Esse dado é importante, pois indica o interesse da universidade em contribuir internamente com a formação prática dos estudantes do curso investigado. Portanto, o setor público se revelou como aquele que mais oferta oportunidade de estágio para os alunos do curso aqui estudado. Por outro lado, no âmbito privado ainda são poucas as oportunidades de estágio para os estudantes. Isso possivelmente se explique pelo fato de o Campus IV da UFPB funcionar em uma comunidade do interior do estado da Paraíba, cujo setor privado é constituído de pequenos comércios e/ou negócios familiares e muitas vezes não possui convênio com a universidade para este fim.

O Gráfico 3 apresenta as cidades que ofertaram estágios nos semestres de 2017.1 e 2017.2.

Gráfico 3 - Cidades que ofertaram estágios nos semestres de 2017.1 e 2017.2

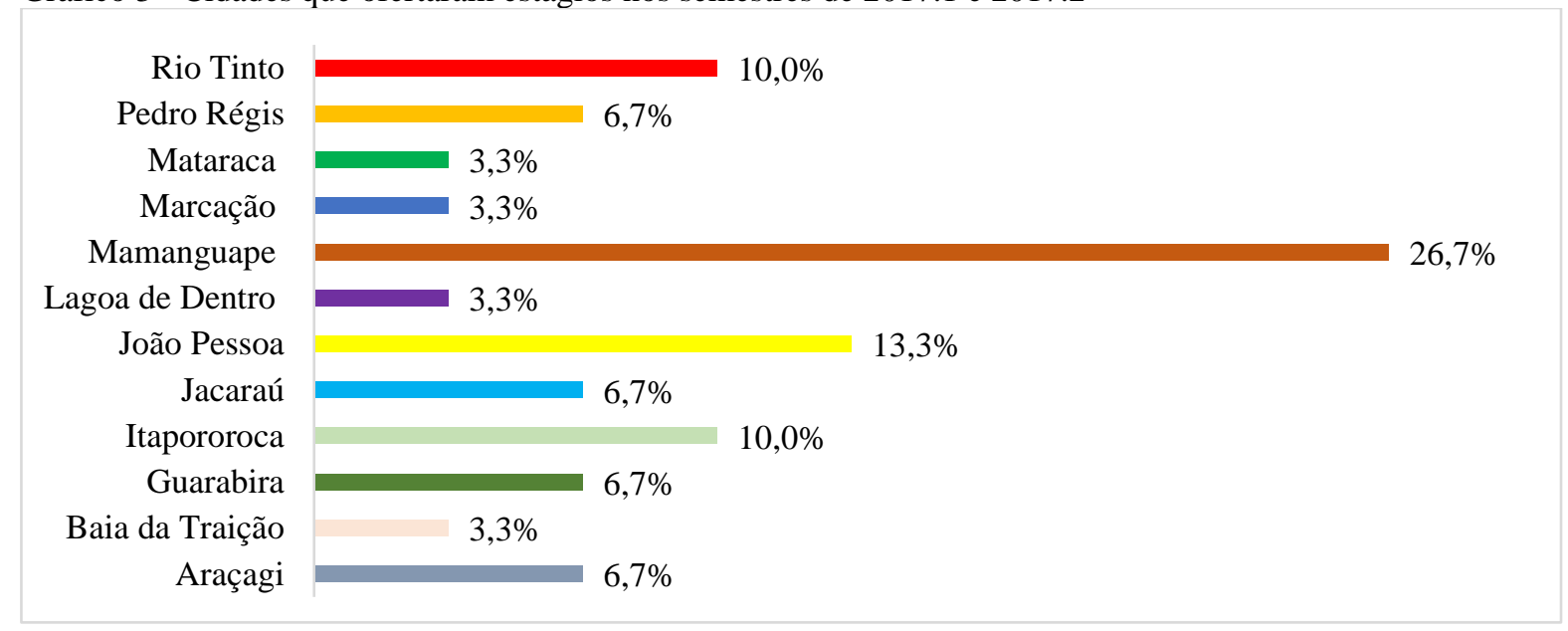

Fonte: Dados de pesquisa (2018).

Nota-se, que a oferta de estágio supervisionado, para os alunos do curso de Secretariado Executivo Bilíngue da UFPB, nesses dois semestres estudados, concentra-se em (11) onze cidades que compõem o Vale do Mamanguape e a capital João Pessoa. Mamanguape representa a cidade que mais oferta vaga de estágio, com um total de $26,7 \%$, seguido da cidade de João Pessoa, com 13,3\% e Rio tinto, com 10,0\%. Conforme comentado anteriormente, o Campus IV 
está localizado no interior da Paraíba, mais precisamente nas cidades de Mamanguape e Rio Tinto e, portanto, isso pode explicar tais cidades se revelarem como aquelas que mais receberam estudantes para realizar suas práticas.

\section{CONSIDERAÇÕES FINAIS}

Este estudo teve como objetivo investigar quais atividades são desenvolvidas pelos estagiários do curso de Secretariado Executivo Bilíngue da UFPB, durante as disciplinas de estágio supervisionado II, III e IV. A partir do mapeamento das atividades presentes nos relatórios de estágio, foi possível constatar que o maior destaque está naquelas relacionadas à assessoria, tais como: redação comercial e atendimento ao público interno e externo.

Os dados revelaram que as atividades desenvolvidas pelos estagiários estão mais voltadas para o campo da assessoria e da consultoria. Percebeu-se ainda que a tradução não apareceu em nenhum relatório de estágio. Possivelmente, isso se explique em função dos estágios terem sido desenvolvidos na sua maioria no âmbito público, cuja necessidade de traduzir textos ainda não faz parte da demanda de trabalho regular.

Verificou-se que as atividades realizadas no estágio II se repetiram nos estágios III e IV. Nos semestres 2017.1 e 2017.2 as atividades que mais se repetiram foram: agendamento; atendimento telefônico; produção de documentos; criação de atas; organização de reuniões, eventos, arquivos, ambiente e gerenciamento de informações.

Observou-se que 30 (trinta) empresas/instituições ofereceram oportunidades de estágio supervisionado. Destacou-se o âmbito público como aquele que mais oferta oportunidade de estágio tendo em vista que 15 escolas públicas, seguidas da UFPB, Campus IV, receberam estagiários do curso investigado durante os semestres de 2017.1 e 2017.2. Ressalta-se, entretanto, que a Universidade Federal da Paraíba, Campus IV, foi a que mais concedeu vagas de estágio em 11 setores na unidade de Mamanguape. O que é considerado um ponto importante, visto que é a principal responsável pela formação do bacharel em Secretariado Executivo Bilíngue e conhecedora dos objetivos desse Curso.

Por fim, sugere-se que essa pesquisa seja replicada nos demais semestres, a fim de dar sequência ao mapeamento e catalogação das atividades desenvolvidas pelos estagiários do curso de Secretariado Executivo Bilíngue da UFPB, além do levantamento das 
empresas/instituições concedentes de estágio para saber se esses fenômenos observados no recorte desta pesquisa se repetem em outros semestres.

\section{REFERÊNCIAS}

AZEVEDO, I; COSTA, S. I. Secretária: um guia prático. 6. ed. São Paulo: SENAC, 2006.

BIANCHI, A. C. M.; BIANCHI, R.; ALVARENGA, M. Manual de Orientação: Estágio Supervisionado. 4. ed. São Paulo: Cengage Learning, 2011.

BIANCHI, A. C. M.; BIANCHI, R.; ALVARENGA, M. Orientação para estágio em secretariado: trabalhos, projetos e monografias. São Paulo: Pioneira Thomson Learning, 2003.

BLOCK, P. Consultoria infalível: Um guia prático, inspirador e estratégico. 3. ed. São Paulo: M. Books, 2013.

BRASIL. Casa Civil. Lei nº11. 788 de 25 de setembro de 2008, Brasília, DF, 2008.

CROCCO, L.; GUTTMANN, E. Consultoria Empresarial. 2. ed. São Paulo: Saraiva, 2010.

DORNELAS, J. C. A. Empreendedorismo: transformando ideias em negócios. 5. ed. Rio de Janeiro: Empreende/LTC, 2014.

FERREIRA, F. D. A atuação do Secretário Executivo no setor público: o caso da Universidade Federal do Ceará. 2011. 118 f. Dissertação (Mestrado em Políticas Públicas e Gestão da Educação Superior) - Universidade Federal do Ceará, Fortaleza-CE, 2011.

GIL, A. C. Como elaborar projeto de pesquisa. 4 . ed. São Paulo: Atlas, 2006.

GIL, A. C. Métodos e técnicas de pesquisa social. 6. ed. São Paulo: Atlas, 2008.

LIMA, T. F.; CANTAROTTI, A. A formação e a construção de competências para a atuação do profissional de secretariado executivo: um estudo de caso em uma empresa júnior. Revista de Gestão e Secretariado. v. 1, n. 2, p. 97 - 98, jul. 2010. ISSN: 2178-9010.

MORETTO, V. P. Construtivismo, a produção do conhecimento em aula. 3. ed. Rio de Janeiro: DP\&A, 2002.

NEIVA, E.G.; D’ ELIA, M. E. S. As novas competências do profissional de Secretariado. 2. ed. São Paulo: IOB, 2009.

NETTO, A. M. Tendências de atuação em RH. In: D’ELIA, B., AMORIM, M., SITA, M. (Org.). Excelência no Secretariado: a importância da profissão nos processos decisórios. Como assessorar e atingir resultados corporativos e pessoais com competência e qualidade. São Paulo: Ser Mais, 2013. p. 385-392.

Revista Expectativa, Toledo/PR, v.20, n. 3, p. 108-130, jul./set., 2021. 
NONATO JR., R. Epistemologia e teoria do conhecimento em secretariado executivo: a fundação das ciências da assessoria. Fortaleza: Expressão Gráfica, 2009.

PAES, V. O. et al. As novas formas de atuação do profissional de secretariado executivo. Revista de Gestão e Secretariado. São Paulo, v. 6, n. 1, p. 103-108, jan./abr. 2015.

PORTELA, K. C. A.; SCHUMACHER, A. J. Estágio supervisionado: teoria prática. Santa Cruz do Rio Pardo, SP: Editora Viena, 2007.

PORTELA, K. C. A.; SCHUMACHER, A. J. Gestão Secretarial: o desafio da visão holística. Cuiabá: Adeptus, 2009.

PRODANOV, C.; FREITAS, E. Metodologia do trabalho científico [recurso eletrônico]: métodos e técnicas da pesquisa e do trabalho acadêmico. 2. ed. Novo Hamburgo: Feevale, 2013.

RICHARDSON. R.J. Pesquisa social: métodos e técnicas. 3. ed. São Paulo: Atlas, 2010.

UFPB - UNIVERSIDADE FEDERAL DA PARAÍBA. Projeto Político-Pedagógico do Curso de Graduação em Secretariado Executivo Bilíngue. João Pessoa: CONSEPE, 2006.

UFPB - Universidade Federal da Paraíba. Resolução nº 01/2009. Regulamento de Estágio do curso de Secretariado Executivo Bilíngue. João Pessoa: Centro de Ciências Aplicadas e Educação da Universidade Federal da Paraíba, 2009. 